\title{
Salas de Atendimento Educacional Especializado (AEE) na rede regular pública de ensino paranaense: desafios, limites e possibilidades do paradigma inclusivo
}

Denize Cristina Kaminski Ferreira*

\section{Resumo}

Este estudo busca promover reflexôes quanto aos desafios, limites e possibilidades da inclusão de alunos com necessidades educacionais especiais na rede regular de ensino, partindo do pressuposto de que as salas de atendimento educacional especializado (AEE) constituem-se como facilitadoras do processo inclusivo nas escolas regulares, com destaque para a atuação do educador enquanto mediador deste processo, uma vez que, no âmbito legal a inclusão é um elemento inerente ao direito social da educação, pautando-se em princípios de justiça social. Esta pesquisa expõe dados empíricos coletados qualitativamente em escolas públicas da regiáo metropolitana de Curitiba, a partir de informaçóes fornecidas pela Coordenação de Educação Especial do referido município, complementadas por questionários semiestruturados aplicados a professores especialistas de salas multifuncionais, evidenciando que tais salas possuem grande relevância na promoção da inclusão, a fim de garantir o efetivo acesso ao direito à educaçáo; conclui-se, portanto, que faz-se necessário fomentar a ruptura de práticas excludentes e discriminatórias, priorizando a emergência de um real paradigma inclusivo; neste estudo ressalta-se ainda a peculiaridade do estado do Paraná, o qual considera como clientela da Educação Especial, conforme determinação federal, alunos com deficiência, transtornos globais do desenvolvimento, altas habilidades/ superdotação, e por normatização estadual, estende seu atendimento a educandos com transtornos funcionais específicos.

Palavras-chave: Inclusão; Alunos com necessidades educacionais especiais; Salas de Atendimento Educacional Especializado (AEE).

* Mestre em Educação pela Universidade Federal do Paraná, Curitiba, Paraná, Brasil. 


\title{
Special educational service rooms in Paraná's public education regular network: challenges, limits and possibilities of the inclusive paradigm
}

\begin{abstract}
This study sought to promote reflections on the challenges, limits and possibilities of inclusion of students with special educational needs in the regular school system, on the premise that the rooms of specialized educational services constitute as facilitators of inclusive process in mainstream schools, highlighting the role of the educator as a mediator of this process, since the legal framework inclusion is an inherent element to the social right education, basing on principles of social justice. This research presents empirical data qualitatively collected in public schools in the metropolitan region of Curitiba, from information provided by the Special Education Coordination of the municipality, complemented by semi-structured questionnaires with specialist teachers, showing that the rooms, they have great importance in promoting inclusion, in order to guarantee effective access to the right to education; concludes, therefore, that it is necessary to promote the breakdown of exclusionary and discriminatory practices, prioritizing the emergence of a real inclusive paradigm; in this study we emphasize still the peculiarity of the state of Paraná, which considers clientele of Special Education as federal determination, students with disabilities, pervasive developmental disorders, high ability, and by state regulation, extends its service to students with specific functional disorders.
\end{abstract}

Keywords: Inclusion; Students with special educational needs; Specialized education rooms.

\section{Introdução}

A partir dos anos 1990, as reivindicaçóes quanto ao direito à educação das pessoas com deficiência $(\mathrm{PcD})$ vêm se tornando pauta cada vez mais recorrente nas discussôes e proposiçôes de políticas públicas na sociedade, premissa esta constante na Declaração de Salamanca, elaborada a partir da Conferência Mundial sobre Necessidades Educacionais Especiais, realizada na Espanha em 1994; tal documento afirma que "as escolas devem acolher todas as crianças, independentemente de suas condiçôes físicas, intelectuais, sociais, emocionais, linguísticas ou outras".

Em consonância às tendências atuais, a legislação vigente - Constituição Federal de 1988, Estatuto da Criança e Adolescente (Lei no 8.069/1990), Lei de Diretrizes e Bases da Educaçáo Nacional (Lei no 9.394/96) e Plano Nacional da Educação (Lei $\mathrm{n}^{\mathrm{o}}$ 13.005/2014) - normatiza que os educandos com necessidades especiais têm o direito a atendimento educacional especializado, preferencialmente na rede regular de ensino; isto é, a inclusão destes alunos é assegurada por lei e perpassa transversalmente todo o sistema educacional brasileiro, da educação infantil ao ensino superior. 
Neste sentido, o fato da inclusão estar assegura na legislação sinaliza um avanço significativo na luta por sua efetivação, pois de acordo com Cury (2002) declarar um direito é retirá-lo do esquecimento e proclamar aos que não sabem ou esqueceram que eles continuam portadores de um direito importante, o que possibilita sua cobrança quanto este direito não for respeitado. A positivação do direito à educação é fundamental para a exigência de seu cumprimento diante de uma possível negação.

Este estudo pauta-se na inferência de que, diante da normatização legal, as salas de atendimento educacional especializado (AEE) constituem-se como facilitadoras do processo de inclusão de alunos com necessidades especiais na rede regular de ensino. Nesta perspectiva, torna-se imperativo discutir e refletir acerca dos desafios, limites e possibilidades contemporâneos que se impóe a este trabalho.

Para melhor abordagem da temática este artigo foi dividido em duas partes, inicialmente expóe-se a perspectiva de educação inclusiva enquanto espaço de efetivação do direito à educação, respeitando as especificidades das pessoas com deficiência (PcD); ademais, pondera acerca dos princípios norteadores e normatizadores, bem como sobre os objetivos, o funcionamento e a clientela atendida pelas salas de atendimento educacional especializado (AEE) na rede regular de ensino público. Num segundo momento, a fim de compreender o contexto atual da inclusão dos alunos com necessidades educacionais especiais, foram analisados dados empíricos coletados a partir de questionários aplicados a três professores especialistas de salas de AEE de um município da regiáo metropolitana de Curitiba, em consonância com informaçôes fornecidas pela Coordenação de Educação Especial do referido município.

Este artigo objetiva fomentar reflexóes acerca da emergência do paradigma inclusivo na contemporaneidade, enfatizando o potencial das salas de atendimento educacional especializado (AEE), reconhecendo-as como facilitadoras da inclusão de alunos com necessidades educacionais na rede regular de ensino, ademais ressalta-se papel do educador enquanto mediador neste processo.

\section{Educação enquanto um direito social}

A educaçáo é um pré-requisito para o acesso a outros direitos do sujeito, ou seja, é inerente ao pleno exercício da cidadania; trata-se, pois de uma condição essencial para a formação de um indivíduo participante em uma sociedade democrática. De acordo com Cury (2002) a educação perpassa a construçáo da cidadania, tanto que não há atualmente nenhum país ou documento internacional que não reconheça legalmente o potencial presente na educação.

Nesta perspectiva, a educação se insere no âmbito dos direitos sociais, assim como a saúde, o trabalho, a alimentaçáo, a moradia, o lazer, a segurança, entre outros, conforme prevê o artigo $6^{\circ}$ da Constituiçáo Federal de 1988. Convém atentar para o fato de que a educação é um direito social de todos os cidadãos brasileiros, independentemente de sua condiçáo social, física, psíquica, cognitiva ou qualquer outro aspecto. Entretanto, é comum associar que as pessoas com deficiência são titulares apenas do direito a um ensino especial em ambientes segregados, o que claramente é inconstitucional, pois não há nenhum ordenamento jurídico que limite seu direito à educação. 
Assim, considerando o papel fundamental da educação na sociedade contemporânea, convém ressaltar que a Constituição da República Federativa do Brasil de 1988 assegura, em seu artigo 208, inciso VII, $\$ 1^{\circ}$, que o acesso ao ensino escolar obrigatório e gratuito é direito público subjetivo ${ }^{1}$, além disso, o não oferecimento desse serviço pelo Poder Público implica em responsabilização da autoridade competente. Assim sendo, evidencia-se a legitimidade da garantia do acesso à educação a todos os brasileiros, sem qualquer tipo de distinção.

Segundo Cury (2002) a discussão acerca do direito à educação pressupóe o direito à diversidade, uma vez que a dialética entre direito à igualdade e direito à diferença pauta-se na constatação de que há uma igualdade intrínseca ao gênero humano, fundamento da cidadania e igualdade entre as pessoas, o que inviabiliza qualquer manifestação de discriminação ou preconceito.

Neste sentido, a delimitação da especificidade do direito à educação para determinados segmentos negligenciados quanto a este direito, dialoga com a perspectiva defendida por Bobbio (2004) de que há quatro etapas para a construção do Estado Democrático de Direito, o que possibilitaria o reconhecimento dos direitos dos sujeitos. A primeira etapa seria a positivaçâo: trata-se da constituiçáo do Direito positivo na força da lei; a segunda etapa é a generalização, ou seja, é reconhecida a igualdade entre os sujeitos de direitos; a terceira é a internacionalizaçâo, vincula-se ao reconhecimento a nível mundial dos direitos humanos; e por fim, há a especificação, ocorrendo o aprofundamento da determinação dos titulares do direito, deixando de se considerar somente os destinatários genéricos (cidadão, ser humano), passando a tratar de sujeitos específicos que historicamente tiveram seus direitos negados (gênero, etnia, idoso, criança, pessoa com deficiência, etc.).

Assim sendo, a educação especial ${ }^{2}$ não se traduz como a negação do direito à educação, ao contrário, é essencialmente válida e recomendável, representa mais um direito daqueles que dele necessitam, além disso, não substitui o ensino regular, trata-se de um complemento na formação de alunos com deficiência, altas habilidades ou transtornos globais do desenvolvimento (e no caso do estado do Paraná, contempla os transtornos funcionais específicos); enquanto modalidade, o ensino especial é transversal a todas as etapas e níveis escolares, da Educação Infantil ao Ensino Superior, de forma que os alunos especiais não podem ser excluídos das salas comuns de ensino regular e encaminhados a escolas e/ou classes especiais para serem escolarizados (MANTOAN, 2013).

Convém esclarecer que quando o atendimento educacional especializado restringe ou impede o direito ao ensino comum, o princípio da igualdade constitucional é lesado, redundando em discriminação. Desde 1989 (art. $8^{\circ}$ da Lei no 7.853) condutas que lesem o direito à educação das pessoas com deficiência, constitui-se crime passível de reclusão (FÁVERO, 2013).

Todavia, conforme Bobbio (2002) há uma distinção entre teoria e prática, de maneira que ambas percorrem duas estradas diferentes com velocidades distintas, no sentido de que com frequência um direito está positivado na legislação, mas o ca- 
minho para sua concretização se mostra tortuoso. Assim sendo, considerando que a legislação determina que o atendimento educacional especializado/educação especial deve ocorrer, preferencialmente, na rede regular de ensino, consta-se que na prática, a consolidação do direito à educação inclusiva tem sido objeto de amplas discussóes, pois tradicionalmente esta clientela recebeu escolarização sendo segregada em escolas ou classes especiais.

Ainda de acordo com Bobbio (2002, p. 23) "o problema fundamental em relação aos direitos do homem, hoje, não é tanto o de justificá-los, mas o de protegê-los. Trata-se de um problema não filosófico, mas político", ou seja, atualmente não se questiona a importância atribuída à educação enquanto um componente inerente ao desenvolvimento de uma nação, todavia, o ponto nevrálgico deste direito é sua efetivação, quando se trata das pessoas com necessidades educacionais especiais, a situação é mais complexa ainda, sobretudo, ao analisar o seu contexto histórico.

\section{Uma abordagem histórica quanto ao atendimento das pessoas com necessidades educacionais especiais}

Até o século XVI não havia preocupaçóes sociais quanto ao oferecimento de atendimento educacional especializado àqueles que necessitassem, assim sendo, historicamente os 'diferentes' se viram à margem e excluídos do processo de escolarização. Apenas a partir do século XVIII, surgem as primeiras instituiçóes filantrópicas voltadas ao atendimento de cegos e surdos, e táo somente, no século XX a sociedade começa a mobilizar-se em torno dos direitos das pessoas com necessidades especiais (FERNANDES, 2006).

Entretanto, há uma grande diferença entre integrar e incluir o portador de necessidades educacionais especiais no espaço escolar. Segundo Mantoan (2003), a discussão em torno desses dois termos gera polêmica nas áreas da educação e da saúde. Para a autora, tais termos evidenciam posicionamentos teórico-metodológicos divergentes, pois integração refere-se especificamente à inserção de alunos com deficiência no sistema educacional, seja em classes comuns ou especiais. Assim, na acepção da integração não caberia à escola qualquer ação de modificação de sua estrutura e práticas pedagógicas, sendo que o aluno deveria adaptar-se ao meio. A inclusão, ao contrário, vincula-se à adaptação do espaço escolar, bem como dos recursos pedagógicos para melhor atender às peculiaridades dos alunos especiais.

Tradicionalmente, paralelamente à rede regular de ensino, criaram-se escolas especiais, para atendimento dos alunos que se destoavam do padrão socialmente convencionado como 'normal', de acordo com Beyer (2006, p. 10), apesar dos esforços para atendimento das pessoas com deficiência, comumente ocorreu a prevalência de um conceito equivocado de que tais pessoas seriam incompletas ou deficientes, desconsiderando seu potencial, de tal forma que "com frequência assistimos a uma práxis social limitadora, subjugadora e castradora dos potenciais humanos e funcionais das pessoas com necessidades especiais", o que tende a limitar seu desenvolvimento e a aquisiçấo de maior autonomia, devido aos preconceitos e cerceamentos sociais, visto que com frequência, os espaços subestimam suas possibilidades e potencialidade, pri- 
vilegiando a intervenção terapêutica-educativa, com o objetivo de aproximar a pessoa do parâmetro da 'normalidade social'.

A inclusão se efetiva somente onde houver respeito à diferença, e consequentemente se as práticas pedagógicas possibilitarem às pessoas com deficiência aprender, sendo reconhecidas e valorizadas suas capacidades e conquistas, para Sartoretto (2013, p. 77-8) "qualquer procedimento, pedagógico ou legal, que não tenha como pressuposto o respeito à diferença e a valorização de todas as possibilidades da pessoa deficiente não é inclusão".

Assim, para que a inclusão de fato se consolide no espaço escolar, é imprescindível a mudança de atitudes e práticas tradicionais, que desconsideram as peculiaridades educacionais desses alunos; é crucial realizar adaptaçóes prediais, curriculares, metodológicas, pedagógicas, avaliativas e outras que se façam necessárias neste processo inclusivo.

Mantoan (2013) defende que a perspectiva de uma escola inclusiva pressupóe uma virada na formação inicial e continuada de professores, enfatizando a discussão de problemas reais, concretos, relativos ao ensino ministrado nas escolas e embasado nas potencialidades dos alunos.

Nesta mesma vertente, Fernandes (2006) ressalta o papel do professor na promoção de uma educação inclusiva, visto que este agente tem ação privilegiada na mediação da formação de culturas inclusivas no ambiente escolar. Tal tendência vem exigindo uma formação inicial mais abrangente dos docentes, bem como a constante busca por aperfeiçoamento profissional, a fim de dar conta das demandas impostas na contemporaneidade.

A inclusão de alunos com necessidades educacionais especiais na rede regular configura-se como um desafio a ser encarado pelos profissionais da educaçáo comprometidos com o acolhimento da diversidade e com a superação da tradicional exclusão daqueles que se destoam do 'padrão de normalidade'; neste contexto, as salas de atendimento educacional especializado constituem-se como importantes aliadas na consolidação do paradigma inclusivo.

\section{O atendimento educacional especializado na rede regular de ensino: espaço de efetivação do direito à educação das pessoas com necessidades especiais}

$\mathrm{O}$ atendimento educacional especializado ocorre em horário oposto ao estabelecido pelo ensino regular, assim sendo, não o substitui; por ser complementar implica, necessariamente, num trabalho diferenciado, não reproduzindo "o mesmo conteúdo nem tampouco a metodologia adotada pela escola comum", assim todo o atendimento pauta-se nas necessidades e particularidades do aluno, porém ambas (AEE e escola regular) precisam acontecer concomitantemente, uma vez que uma beneficia o trabalho da outra (BATISTA, 2013, p. 122).

De acordo com a Resoluçáo CNE/CEB no 4 de 2 de outubro de 2009, a qual institui Diretrizes Operacionais para o Atendimento Educacional Especializado na Educaçâo Básica, na modalidade Educação Especial: 
Art. $1^{\circ}[\ldots]$ os sistemas de ensino devem matricular os alunos com deficiência, transtornos globais do desenvolvimento e altas habilidades/superdotação ${ }^{3}$ nas classes comuns do ensino regular e no Atendimento Educacional Especializado (AEE), ofertado em salas de recurso multifuncionais ou em centros de Atendimento Educacional Especializado na rede pública ou de instituições comunitárias, confessionais ou filantrópicas sem fins lucrativos.

Art. 2० O AEE tem como função complementar ou suplementar a formação do aluno por meio da disponibilização de serviços, recursos de acessibilidade ou estratégias que eliminem barreiras para sua plena participação na sociedade e desenvolvimento de sua aprendizagem.

Em caráter complementar, a Instrução Normativa SEED/SUED-PR $\mathrm{n}^{\circ}$ 016/2011, emitida pelo Governo do Estado do Paraná, a fim de estabelecer critérios para o atendimento educacional especializado na rede pública de Educação Básica paranaense, determina que a sala de recurso multifuncional caracteriza-se pelo atendimento educacional especializado de natureza pedagógica, a fim de complementar a escolarização dos alunos que apresentam altas habilidades/superdotação, deficiência intelectual, física neuromotora, transtornos globais do desenvolvimento e transtornos funcionais especificos [sem grifos no texto de lei]. Dessa maneira, tal documento amplia a possibilidade de atendimento do AEE, integrando mais uma categorização, não contemplada na legislação federal: alunos com transtornos funcionais específicos, ou seja, com dificuldades do desenvolvimento de funcionalidades intrínsecas do sujeito, sem o comprometimento intelectual do mesmo, isto é, trata-se de alteraçóes manifestadas por dificuldades significativas, seja na aquisição e uso da audição, fala, leitura, escrita, raciocínio ou habilidades matemáticas, na atenção e concentraçãó .

Acerca da clientela atendida pelo AEE (pessoas com deficiência, transtornos globais do desenvolvimento, altas habilidades/superdotação e transtornos funcionais específicos), convém salientar que o aluno com necessidades educacionais especiais não é uma pessoa ontologicamente deficiente, é um ser como todos os demais, entretanto, possui particularidades no que tange à sua aprendizagem, assim sendo, embora seja "alguém que reúne uma série de atributos que podem pesar desfavoravelmente para uma aprendizagem significativa e eficaz", é uma pessoa como as demais, "cujo um dos seus atributos é não ouvir, não ver, não andar, e assim por diante" (BEYER, 2006, p. 09).

Cada aluno é um sujeito único que não se reduz a categorizaçôes ou rotulaçóes, sendo que sua complexidade náo pode ser mensurada de fora, ademais estes necessitam de situaçóes estimuladoras para que avancem nos aspectos inerentes à sua personalidade e aprendizagem (MANTOAN, 2013).

Com relaçáo ao profissional habilitado para conduzir o trabalho pedagógico nas salas e centros de AEE, de acordo com o artigo 12 da Resolução CNE/CEB no 4/2009, para atuar no atendimento educacional especializado, o professor deve ter formação inicial que o habilite para exercício da docência e formação específica na 
educação especial, devendo realizar esse atendimento de forma complementar ou suplementar à escolarização, considerando as habilidades e as necessidades específicas do público alvo da educação especial'.

Nesta perspectiva, o professor especialista tem como objetivo proporcionar ao aluno com deficiência aquilo que é específico à sua necessidade educacional, de maneira a auxiliá-lo a romper as barreiras que impeçam seu desenvolvimento, assim sendo, o AEE realiza práticas educacionais específicas, como reeducação visual, orientação espacial, estímulo da mobilidade, desenvolvimento de comunicação alternativa, uso de tecnologias assistivas ${ }^{6}$, entre outros.

Comumente as limitaçôes dos indivíduos com necessidades especiais tendem a tornar-se um obstáculo para o seu aprendizado, assim sendo, desenvolver recursos de acessibilidade pode ser apontada como uma maneira concreta para neutralizar as barreiras causadas pela deficiência, permitindo que o mesmo seja inserido em ambientes ricos para aquisição de conhecimento e cultura (GALVÃO FILHO; DAMASCENO, 2006).

Considerando o exposto, este estudo justifica-se diante da possibilidade de sinalizar possíveis contribuições na área, sobretudo, ao fomentar discussōes e reflexóes quanto ao papel das salas de atendimento educacional especializado (AEE) no contexto da inclusão.

\section{Pesquisa empírica: o atendimento educacional especializado na rede regular de um município da Região Metropolitana de Curitiba-PR}

A legislação vigente pressupóe a promoção de um paradigma inclusivo, assim no intuito de captar elementos empíricos acerca da inclusão de alunos com necessidades educacionais especiais na rede regular de ensino, foi realizada uma pesquisa, com posterior análise crítica dos dados coletados à luz do referencial teórico construído a partir de pesquisa bibliográfica e documental, as quais possibilitaram o contato com o conhecimento produzido a respeito da temática em questão.

\section{Método}

Este estudo se insere no campo das pesquisas qualitativas, pois pauta-se na obtenção de dados descritivos sobre a realidade estudada, mediante o contato direto do pesquisador com a problemática a ser analisada (LÜDKE; ANDRÉ, 1986).

A fim de perceber os limites, desafios e possibilidades de atuaçáo das salas de atendimento educacional especializado (AEE) no processo inclusivo, foram analisadas informaçôes fornecidas pela Coordenação de Educação Especial de um município da região metropolitana de Curitiba, posteriormente foram aplicados questionários semiestruturados ${ }^{7}$ aos sete professores das salas multifuncionais do referido município; os questionários foram encaminhados aos docentes por intermédio do coordenador municipal de Educaçáo Especial, sendo que o preenchimento dos referidos instrumentos era opcional, assim obteve-se o retorno de três destes. Optou-se 
pela aplicação de questionário, pois de acordo com Severino (2007, p. 125), este instrumento é composto por um "conjunto de questôes, sistematicamente articuladas, que se destinam alevantar informaçóes escritas por parte dos sujeitos pesquisados, com vista a conhecer a opiniấo dos mesmos sobre os assuntos em estudo". Nesse sentido, o mesmo mostrou-se com um recurso valioso para a coleta de dados, a fim de responder à problemática deste estudo.

\section{Resultados e discussão}

Conforme dados fornecidos Coordenação de Educação Especial da Secretaria Municipal de Educação, o município pesquisado possui onze escolas municipais e uma instituição filantrópica - que atendem às séries iniciais do ensino fundamental, das quais sete possuem salas de recursos multifuncionais para atendimento dos alunos com necessidades educacionais especiais; de maneira que alguns discentes não são atendidos nas escolas onde estấo matriculados no ensino regular, deslocam-se até a instituição escolar mais próxima para receber tal atendimento.

Diante dos dados coletados foi possível perceber que dos 4.056 (quatro mil e cinquenta e seis) alunos da rede municipal matriculados no primeiro semestre de 2014, um percentual de 5,2\%, ou seja, 129 (cento e vinte e nove) recebem atendimento educacional na modalidade Educação Especial na rede regular. Convém informar ainda que, no município objeto da pesquisa empírica há uma escola especial (Apae), a qual atende a 105 (cento e cinco) discentes.

Dentre a clientela atendida nas referidas salas de AEE, há alunos desde a Educação Infantil até o $5^{\circ}$ ano do Ensino Fundamental, com idades que variam de 05 a 14 anos de idade. Segundo as informaçóes coletadas verificou-se que a maior demanda para atendimento são as deficiências intelectuais, totalizando 81 atendimentos (63\%); os transtornos funcionais específicos (TDAH) representam 11 dos casos (8,5\%); há 07 alunos com a deficiência física/neuromotora (5\%); 06 discentes apresentam algum transtorno global do desenvolvimento (5\%); existem 02 casos de deficiência visual $(1,5 \%)$ e há ainda 22 casos não especificados $(17 \%)$, sendo que estes últimos estão em processo de avalição médica para constatação da deficiência/ transtorno; convém atentar para o fato de que nenhum aluno surdo ou com superdotação/alta habilidade é atendido pelo AEE no município pesquisado.

Os professores responsáveis pelas salas multifuncionais, participantes da pesquisa, possuem magistério em nível médio, são pedagogos e especialistas em Educação Especial, assim sendo, a titulação dos mesmos atende ao contido no artigo $12 \mathrm{da}$ Resolução CNE/CEB no 4/2009, quanto à formação específica dos profissionais do AEE.

A fim de resguardar a identidade dos participantes, não serão citados nomes/ escolas, sendo que os mesmos seráo identificados pelo codinome PE (professor especialista) 1, 2 e 3; faz-se necessário esclarecer ainda, que a numeraçáo vincula-se à ordem entrega dos questionários. 
O PE 1 atua há mais de 15 anos na rede pública municipal, porém na sala de AEE está há menos de um ano, já tendo tido contato com alunos especiais antes de exercer a atual função, com discentes inclusos em sala regular (deficiência auditiva). O referido profissional sente-se preparado para trabalhar com alunos especiais, entretanto sente necessidade de aprimorar-se frequentemente, mediante pesquisas, para melhor atender aos educandos.

O PE 2 atua na rede pública municipal pelo período de 0 a 5 anos, atende no AEE há menos de um ano, afirmou não ter tido nenhum tipo de contato com alunos especiais antes de desempenhar a atual função, ademais sente-se preparado para trabalhar com pessoas com necessidades educacionais especiais.

O PE 3 está na rede pública municipal entre 11 a 15 anos, estando à frente da sala de AEE entre 2 a 3 anos, já tendo tido contato com alunos especiais antes de exercer a atual função, em escola e classe especial, além de ter atendido alunos inclusos em sala regular (condutas típicas). O referido profissional acredita que nem sempre está preparado para trabalhar com alunos que necessitem de atendimento educacional especializado.

Quando questionou-se quais seriam deficiências e transtornos mais difíceis de se atender no AEE, o PE 1 e 3 destacaram a deficiência intelectual, pois o progresso mostra-se moroso, sobretudo, diante da falta de compreensão da função da escrita como representação da linguagem e a dificuldade na comunicação. Já o PE 2 destacou a dificuldade no atendimento dos casos de TDAH e de Transtorno Opositor Desafiador, em virtude da dificuldade de conseguir atingir os objetivos esperados.

Os três professores afirmam perceber avanços na aprendizagem e socialização dos alunos atendidos nas salas de atendimento especializado, mesmo que em alguns casos, os progressos não sejam tão significativos, considerando os diferentes tipos de deficiência/transtorno atendidos, há situações em que os avanços são paulatinos e mais lentos, porém visíveis.

Acerca das principais atividades/intervenções realizadas no AEE, são destacados os seguintes elementos:

$\mathrm{O}$ atendimento é feito em pequenos grupos, com a finalidade de desenvolver ao máximo as potencialidades dos alunos valorizando seu conhecimento prévio, utilizando materiais e jogos pedagógicos conforme as necessidades, interesses e a idade do aluno: socialização, estimular o desenvolvimento da linguagem, desenvolver a autonomia, favorecer a compreensão de conhecimentos, entre outros - (PE 1).

Atividades lúdicas, jogos, música, sempre buscando a interação do aluno com as atividades propostas. E a socialização tornando as atividades prazerosas - (PE 2).

Principalmente jogos e atividades diferenciadas de acordo com as necessidades e dificuldades que os alunos apresentam, partindo 
sempre de suas potencialidades e habilidades (jogos diversos e virtuais, caça-palavras, cruzadinhas, etc.) - (PE 3).

Conforme exposto por Batista (2013) o atendimento educacional especializado não deve pautar-se nas mesmas práticas do ensino regular, deve ser complementar, propondo metodologias diferenciadas e atendimento individualizado, neste sentido, observa-se que os professores especialistas do município objeto de estudo priorizam esta premissa em suas funçóes, o que efetivamente beneficia o desenvolvimento do educando.

De acordo a Resoluçáo no 4/2009, dentre as atribuições do professor de AEE, destaca-se a necessidade de articulação e orientação aos professores das classes comuns, nesta perspectiva os três professores especialistas afirmam realizar este trabalho, nas permanências, intervalos e conselhos de classe bimestrais, realizando trocas de experiências e adaptaçôes curriculares; inclusive o PE 3 ponderou que faz uso de um caderno de comunicação, no qual constam cópias de laudos e pareceres, facilitando o trabalho colaborativo.

Foi possível constatar que além dos alunos matriculados regularmente nas salas de AEE (com laudo), ocorre ainda o atendimento informal de discentes em processo de avaliaçáo ou sem atestado médico, diante da necessidade educacional especial evidenciada, no intuito de buscar efetivar o direito à educação.

Dentre as principais dificuldades encontradas pelos professores especialistas para atuar no contexto da educação inclusiva na rede regular de ensino, foram destacados os seguintes aspectos: assiduidade do aluno, acompanhamento familiar, quantidade de alunos nas salas regulares, capacitaçáo/qualificação dos profissionais, aceitação do aluno a incluir e insegurança, tais aspectos evidenciam a necessidade da superação do tradicional atendimento destinado a um 'aluno idealizado e padronizado', pressupondo, por conseguinte, a valorizaçáo e o respeito às diferenças do sujeito concreto.

A fim de romper com a exclusão e o preconceito, a inclusão escolar não se limita meramente à população com necessidades educacionais especiais, mas envolve toda a sociedade, exigindo a ruptura de paradigmas historicamente construídos, na busca pela construção de uma sociedade menos desigual (MAZZILO, 2009).

\section{Considerações finais}

Ao analisar a legislaçáo atual, é possível inferir que se avançou muito em direção à efetivação do direito à educaçáo dos alunos com necessidades especiais em escolas regulares inclusivas, todavia, na prática ainda existem desafios a serem superados, o que requer a alteração de práticas educativas excludentes tradicionalmente consolidadas.

Os alunos com necessidades educacionais especiais juridicamente são titulares do direito social da educaçáo, ministrada preferencialmente na rede regular, lhes sendo garantida a oferta de Educação Especial, enquanto uma modalidade transversal ao ensino; nesta perspectiva, as salas de atendimento educacional especializado 
mostram-se como um excelente recurso facilitador da inclusão, considerando que a Educação Especial deixou de ser uma prática substitutiva à parte, passando a ser uma prática complementar e interligada à escolaridade comum.

Convém salientar que a inclusão não é uma concessão à pessoa com deficiência, trata-se, pois, de um direito constitucional que precisa ser assegurado àqueles que necessitarem, garantindo-lhes o acesso e permanência no sistema escolar regular, resguardando suas especificidades de aprendizagem, possibilitando o maior desenvolvimento possível de suas potencialidades.

Conforme pondera a Declaração Universal dos Direitos Humanos, as pessoas nascem iguais em direitos e em dignidade, todavia, cada ser pode apresentar peculiaridades que lhes são próprias, o que não minimiza seus direitos, mas exige esforços ainda maiores para garantir sua efetivaçáo. Neste contexto, o atendimento educacional especializado ofertado, preferencialmente na rede regular de ensino, nas salas e centros de AEE de maneira complementar ao trabalho da escola comum, configurando-se numa possibilidade efetiva de inclusão escolar dos alunos com necessidades educacionais especiais.

Com a pesquisa empírica realizada, é possível sinalizar que o atendimento educacional especializado pode viabilizar a inclusáo na rede regular de ensino, embora se trate de um estudo qualitativo, o que náo permite generalização de dados, as inferências deste artigo poderão contribuir com as discussôes na área das políticas públicas inclusivas; diante das reflexóes produzidas é importante destacar que é fundamental promover a formação dos professores enquanto especialistas na área, para que estes possam fazer intervenções adequadas, atuando efetivamente como mediadores no processo inclusivo; ademais as práticas desenvolvidas na modalidade de ensino da Educação Especial devem pautar-se em metodologias diferenciadas, considerando a especificidade da deficiência/transtorno/ necessidade educacional especial do educando em atendimento, no intuito de auxiliá-lo a desenvolver suas potencialidades; outro elemento relevante é a necessária articulação entre educador da sala de aula regular e da sala de AEE, visto que seus trabalhos pedagógicos podem e devem ser complementares, sendo crucial desmistificar estereótipos e desconstruir preconceitos e discriminaçóes em torno da clientela atendida pela Educação Especial.

Assim sendo, a natureza da ação pedagógica realizada nas salas de atendimento educacional especializado (AEE) vincula-se à complementação do trabalho desenvolvido nas classes comuns, não podendo ser substituído, devendo ocorrer de forma concomitante e integrada, o que pressupóe a necessidade de formaçáo especializada, não somente do responsável pelo AEE, mas inclusive do professor regente da rede regular.

A fim de efetivar o direito de todos à educação torna-se imperativo a promoção de atitudes voltadas para a superação de práticas tradicionalmente excludentes, por açóes vinculadas ao emergente paradigma inclusivo, o que tende a trazer inúmeras contribuiçóes por prezar pela valorização e respeito à diversidade inerente ao gênero humano. 


\section{Referências}

BATISTA, C. A. M. Atendimento educacional especializado para pessoas com deficiência mental. In: MANTOAN, M. T. E. (Org.). O desafio das diferenças nas escolas. Petrópolis: Vozes, 2013.

BEYER, H. O. A educação Inclusiva: ressignificando conceitos e práticas da educação especial. Revista da Educaçáo Especial, v. 1 n. 02, p. 08-12. Brasília: ago. 2006.

BOBBIO, N. A era dos direitos. Rio de Janeiro: Elsevier, 2004.

BRASIL. Constituiçáo Federal de 1988. Disponível em: <www.planalto.gov.br/ccivil_03/constituicao/constituicao.htm>. Acesso em: 01 abr. 2014.

Lei no 7.853 de 24 de outubro de 1989. Dispóe sobre o apoio às pessoas portadoras de deficiência [...] Disponível em: <http://www.planalto.gov.br/ccivil_03/leis/17853.htm>. Acesso em: 01 out. 2014

Lei no 8069 de 13 de julho de 1990. Estatuto da Criança e do Adolescente. Disponível em: <www. planalto.gov.br/ccivil_03/leis/18069.htm>. Acesso em: 01 abr. 2014.

Lei no 9394 de 20 de dezembro de 1996. Lei de Diretrizes e Bases da Educação Nacional. Disponível em: <http://www.planalto.gov.br/ccivil_03/Leis/L9394.htm>. Acesso em: 01 abr. 2014.

Lei no 13.005 de 25 de junho de 2014. Plano Nacional de Educação. Disponível em: <http://www2. camara.leg.br/legin/fed/lei/2014/lei-13005-25-junho-2014-778970-publicacaooriginal-144468-pl.html>. Acesso em: 21 ago. 2014.

Resoluçáo CNE/CEB no 4 de 2 de outubro de 2009. Diretrizes Operacionais para o Atendimento Educacional Especializado na Educação Básica, na modalidade Educação Especial. Disponível em: <http:// portal.mec.gov.br/dmdocuments/rceb004_09.pdf>. Acesso em: 01 out. 2014.

CURY, C. R. J. Direito à educaçáo: direito à igualdade, direito à diferença. Cadernos de Pesquisa, n. 116, jul./2002.

FÁVERO, E. A. G. Alunos com deficiência e seu direito à educaçáo: trata-se de uma educaçáo especial? In: MANTOAN, M. T. E. (Org.). O desafio das diferenças nas escolas. Petrópolis: Vozes, 2013.

FERNANDES, S. Fundamentos para Educaçáo Especial. Curitiba: IBPEX, 2006.

GALVÃO FILHO, T. A.; e DAMASCENO, L. L. Tecnologias Assistivas para autonomia do aluno com necessidades educacionais especiais. Revista da Educaçáo Especial, v. 1 n. 02, p. 25-39. Brasília: ago. 2006.

LÜDKE, M,; ANDRÉ, M. E. D. A. Pesquisa em Educaçáo: abordagens qualitativas. São Paulo: EPU, 1986

MANTOAN, M. T. E. Inclusáo escolar. O que é? Por quê? Como se faz? São Paulo: Moderna, 2003.

Inclusão escolar: caminhos, descaminhos, desafios, perspectivas. In: MANTOAN, M. T. E. (Org.). O desafio das diferenças nas escolas. Petrópolis: Vozes, 2013.

MAZZILO, I. B. C. V. Inclusão escolar: dissonâncias entre teoria e prática. In: DEILOU, et al. (Org.). Educaçáo inclusiva. Curitiba: IESDE, 2009.

ONU (Organização das Naçôes Unidas). Declaraçáo Universal dos Direitos Humanos.

PARANÁ. Instruçáo Normativa SEED/SUED no 016/2011. Estabelece critérios para o atendimento educacional especializado em Sala de Recursos Multi funcional Tipo I, na Educaçáo Básica. Disponível em: <www. educacao.pr.gov.br/arquivos/File/instrucoes/Instrucao162011.pdf >. Acesso em: 01 out. 2014.

SARTORETTO, M. L. Inclusão: da concepção à ação. In: MANTOAN, M. T. E. (Org.). O desafio das diferenças nas escolas. Petrópolis: Vozes, 2013.

SEVERINO, A. J. Metodologia do Trabalho Científico. São Paulo: Cortez, 2007.

UNESCO. Declaraçáo de Salamanca: sobre princípios, políticas e práticas na área das necessidades educativas especiais. Disponível em: <http://portal.mec.gov.br/seesp/arquivos/pdf/salamanca.pdf>. Acesso em: $01 \mathrm{abr}$. 2014.

\section{Notas}

${ }^{1}$ De acordo com Cury (2002), um direito público subjetivo é aquele pelo qual seu titular pode exigir direta e imediatamente do Estado, o cumprimento de um dever e de uma obrigação, trata-se de uma prerrogativa própria do sujeito, essencial para sua personalidade e cidadania. 
${ }^{2}$ A educação especial é uma modalidade de ensino regulamentada pelos artigos 58 a 60 da Lei de Diretrizes e Bases da Educaçáo Nacional no 9.394 de 20 de dezembro de 1996.

${ }^{3}$ Conforme o art. $4^{\circ}$ da Resoluçáo no 4/2009, o público alvo do AEE são: alunos com deficiência (aqueles que têm impedimento de longo prazo de natureza física, intelectual, mental ou sensorial); os alunos com transtornos globais do desenvolvimento (aqueles que apresentam um quadro de alteraçóes no desenvolvimento neuropsicomotor, comprometimento nas relaçôes sociais, na comunicação ou estereotipias motoras, incluindo-se nessa definiçáo alunos com autismo clássico, síndrome de Asperger, síndrome de Rett, transtornos desintegrativos da infância - psicoses e transtornos invasivos sem outra especificação); e alunos com altas habilidades/superdotação (aqueles que apresentam um potencial elevado e grande envolvimento com as áreas do conhecimento humano, isoladas ou combinadas: intelectual, liderança, psicomotora, artes e criatividade) - [sem grifos no textos de lei].

${ }^{4}$ Conforme Instrução Normativa SEED/SUED-PR no 016/2011, os transtornos funcionais específicos contemplam: distúrbios da aprendizagem (dislexia, disortografia, disgrafia e discalculia) e transtornos do déficit de atenção e hiperatividade $(\mathrm{TDA} / \mathrm{H})$.

${ }^{5}$ De acordo com o art. 13 da Resolução no 4/2009, as atribuiçôes do professor de AEE contemplam: elaboração, execuçáo e avaliaçáo do plano de AEE do aluno; definiçăo do cronograma e das atividades do atendimento do aluno; organização de estratégias pedagógicas e identificação e produção de recursos acessíveis; ensino e desenvolvimento das atividades próprias do AEE, tais como: Libras, Braille, orientação e mobilidade, Língua Portuguesa para alunos surdos; informática acessível; Comunicação Alternativa e Aumentativa - CAA, atividades de desenvolvimento das habilidades mentais superiores e atividades de enriquecimento curricular; acompanhamento da funcionalidade e usabilidade dos recursos de tecnologia assistiva na sala de aula comum e ambientes escolares; articulaçấo com os professores das classes comuns, nas diferentes etapas e modalidades de ensino; orientaçáo aos professores do ensino regular e às famílias sobre os recursos utilizados pelo aluno; e interface com as áreas da saúde, assistência, trabalho e outras.

${ }^{6}$ Tecnologia Assistiva é toda e qualquer ferramenta, recurso ou processo utilizado com a finalidade de proporcionar uma maior independência e autonomia à pessoa com deficiência. Sáo consideradas Tecnologias Assistivas, portanto, desde artefatos simples, como uma colher adaptada ou um lápis com uma empunhadura mais grossa para facilitar a preensão, até sofisticados programas especiais de computador que visam a acessibilidade (GALVÃO FILHO; DAMASCENO, 2006).

${ }^{7} \mathrm{O}$ questionário semiestruturado aplicado possuía uma pequena nota explicativa quanto à natureza da pesquisa, além de assegurar que as informaçôes coletadas seriam tratadas com sigilo absoluto, sendo garantido o anonimato das instituiçóes de ensino, do município e dos participantes deste estudo. O referido instrumento continha doze perguntas norteadoras, distribuídas em três eixos temáticos, a saber: $A$ ) formação e tempo de atuação no magistério (rede regular e educação especial); $B$ ) a especificidade do trabalho na sala de atendimento educacional especializado (caracterização do alunado; atividades desenvolvidas; avanços, limites/dificuldades encontradas); e $C$ ) articulaçăo do trabalho pedagógico com os docentes da sala regular.

\section{Correspondência}

Denize Cristina Kaminski Ferreira - Rua Waldomiro Souza Hathy, 294-D, Centro, CEP: 83430-000, Campina Grande do Sul - Paraná, Brasil.

E-mail: denize_fabio@hotmail.com

Recebido em 04 de março de 2015

Aprovado em 26 de outubro de 2015 